\title{
Xenon Xe-133
}

National Cancer Institute

\section{Source}

National Cancer Institute. Xenon Xe-133. NCI Thesaurus. Code C47784.

A radioisotope of xenon, an element with 54 protons, having gamma emissions and a physical half-life of 5.27 days. Xenon-133 is used in the study of pulmonary function and organ blood flow. 